\title{
O rádio informativo e a economia política da comunicação
}

\author{
Veridiana Pivetta de Mello
}

\section{A economia política da comunicação}

programação informativa de rádio se transformou consideravelmente desde
que o meio viveu sua primeira experiência oficial há mais de 90 anos. Na
atualidade a programação informativa se organiza por parâmetros empresariais que refletem o modo capitalista de produção. Numa pesquisa sobre a história do rádio no país, Ferraretto (2009) observa a relação direta entre o desenvolvimento do capitalismo e deste meio de comunicação. Conforme o autor (2009: 94), a indústria de radiodifusão sonora, como empreendimento capitalista, foi examinada em seu estudo "como um setor econômico específico do qual fazem parte as empresas que recebem outorga do Estado para a operação de emissoras voltadas, de modo prioritário, à obtenção do lucro e, por extensão, à acumulação de capital".

Boa parte dos trabalhos sobre o tema faz referência à definição de Mosco (1996: 25), segundo a qual se pode pensar a "economia política como o estudo das relações sociais, particularmente as relações de poder, que mutuamente constituem a produção, distribuição e consumo de recursos". O autor chama a atenção que os produtos de comunicação tais como jornais, livros, vídeos e filmes são considerados recursos primários. A formulação, portanto, é bastante adequada para o campo da comunicação, pois dá ênfase às forças fundamentais do mercado e dos processos de trabalho. Uma conceituação mais abrangente e ambiciosa, assinala Mosco (1998), de economia política, refere-se ao estudo do controle - da organização interna da sociedade e dos processos de adaptação às mudanças - e da sobrevivência - o modo como as pessoas produzem aquilo que é necessário para a reprodução e continuida- 
de sociais - na vida social. Sendo que os processos de controle são de caráter mais político, enquanto os de sobrevivência dizem respeito ao âmbito econômico.

No sentido de uma compreensão mais aprofundada da economia política convém destacar o que Mosco (1996) descreve como as quatro qualidades centrais que caracterizam a abordagem: a mudança social e histórica; a totalidade social; a filosofia moral e a práxis. Conforme o autor, a economia política tem se empenhado prioritariamente no sentido de entender as mudanças sociais e as transformações históricas desde o seu início.

Para teóricos clássicos como Adam Smith, David Ricardo e John Stuart Mill, isto significou compreender a grande revolução capitalista, a convulsão que transformou sociedades baseadas principalmente no trabalho agrícola em comerciais, manufatureiras e, posteriormente, sociedades industriais. Para economistas políticos críticos como Marx, significou examinar as forças dinâmicas do capitalismo responsáveis pelo seu crescimento e mudança (Mosco, 1996: 27).

Contudo, os economistas políticos contemporâneos enfocam agora questões como a transição de uma economia industrial para uma economia de serviços. Os estudos de informação e dos meios de comunicação, segundo Mosco (1998) desempenham uma função importante nesta pesquisa, porque suas indústrias e tecnologias são elementos primordiais na criação de uma economia de serviços. Além disso, é o aparecimento das indústrias da mídia no século XX que teria provocado a aproximação da economia política com a comunicação.

A segunda característica central da economia política é a totalidade social - as relações sociais que compõem as esferas econômica, política, social e cultural da vida. Mosco (1996) explica que muitos economistas-políticos se interessaram em usar a economia política como um meio de compreender o todo social, mesmo reconhecendo que esta era interligada com outros ramos da chamada filosofia social. "A economia política começa a partir de aspectos particulares da vida social, mas é também um guia para entender as relações que prevalecem entre os muitos aspectos da vida social" (Mosco, 1996: 30). De acordo com Mosco (1996: 31) entram em conflito com a maioria dos aspectos centrais "da teoria econômica política, mas reconhecem e procuram dar conta, de maneiras distintas, das relações entre o econômico e o político, bem como entre estes e a mais ampla arena de instituições sócio-culturais e práticas".

A filosofia moral é a terceira característica substantiva da economia política. Ela se refere tanto aos valores que orientam os comportamentos sociais, quanto às concepções que norteiam as adequadas práticas sociais. $\mathrm{Na}$ atualidade, aponta Mosco (1996), o debate sobre as fronteiras da filosofia moral continua em disputa, porém, a 
tendência da economia política é valorizar o ponto de vista moral filosófico que coloca em destaque a extensão da democracia para todos os aspectos da vida social. Assim, ter a filosofia moral como um dos pontos centrais da economia política significa reconhecer a participação pública e a igualdade de direitos como valores fundantes, num mundo dominado pelo poder político e econômico das grandes empresas.

Por fim, a quarta característica central da economia política é a práxis, unidade fundamental do pensar e do fazer. Segundo Mosco (1996: 37) "a práxis se refere à atividade humana e, especificamente, à atividade livre e criativa pela qual as pessoas produzem e transformam o mundo e a si mesmas". Os economistas políticos concordam que a separação entre teoria e prática, comum no ambiente acadêmico, é artificial e deve ser superada.

A economia política da comunicação reúne a capacidade de esclarecer as questões contemporâneas criticamente, pois se ocupa da expansão da lógica capitalista para a área da comunicação e da cultura. As pesquisas nesta perspectiva precisam estabelecer-se, conforme Bolaño (2008: 61), "na dupla contradição existente entre capital e trabalho, de um lado, economia e cultura, de outro, sendo uma alternativa para a construção de um paradigma teórico geral, centrado no entendimento do fenômeno cultural e comunicacional”, para a compreensão do modo de produção capitalista na atual fase de seu desenvolvimento.

Não se trata de compreender os meios de comunicação como aparatos ideológicos, aponta Zallo (1988), mas, entendê-los como indústrias, com funções diretamente econômicas, como criadores de mais-valia, através da produção e circulação de mercadorias, e com funções econômicas indiretas, através da publicidade, na criação de mais-valia dentro de outros setores de produção de mercadorias.

Na visão de Moragas (2011) a EPC continua questionando a economia política burguesa, mas retifica a concepção inicial do marxismo em relação ao determinismo entre os modos de produção e os sistemas simbólicos, ampliando sua análise para a produção, distribuição e consumo destes bens. "A economia política da comunicação equivale, então, à problematização, à crítica, da influência do sistema capitalista na comunicação, bem longe de outras abordagens, tais como as colocadas pela economia das empresas de comunicação", assinala o autor (2011: 217).

Para um melhor entendimento da perspectiva teórica é importante explicar o uso, recorrente, do termo indústrias culturais, no plural. De acordo com Fonseca (2008) os pesquisadores da economia política da comunicação irão afirmar que a indústria cultural como unidade não existe, pois cada indústria expressa formas de padronização próprias que obedecem a uma lógica particular. "A nova concepção representa uma ruptura com os frankfurtianos", aponta Fonseca (2008: 69), que utilizam o termo indústria cultural, no singular, para expressar que a produção cultural tem a mesma racionalidade técnica, organização e planejamento administrativo, que a de uma fábrica moderna com seu consumo de massa. 
De outro modo, o termo no plural traz a noção que existem nas indústrias culturais uma natureza diferente das outras indústrias, uma forma de produção peculiar e uma especificidade de sua produção em relação à sociedade, esclarece Zallo (1988). Assim, os conteúdos e formas são parte dos sistemas de ideias e valores de uma sociedade, contudo, são também gerados industrialmente, seja na forma de produção material ou imaterial (bens ou serviços) cristalizados como mercadorias culturais. $\mathrm{O}$ autor compreende indústrias culturais como:

(...) um conjunto de setores, segmentos e atividades industriais auxiliares produtoras e distribuidoras de mercadorias com conteúdos simbólicos, concebidas por um trabalho criativo, organizadas por um capital que se valoriza e destinadas, finalmente, aos mercados de consumo, com uma função de reprodução ideológica e social (Zallo, 1988: 26).

As indústrias culturais, portanto, designam as produções culturais das várias áreas da comunicação e da cultura que têm sua natureza, forma de produção e de consumo próprias, essencialmente diferenciadas de outras indústrias, mas são, também, empresas que reproduzem o modo capitalista de produção, atualmente, unindo a indústria de produção de conteúdo com a indústria microeletrônica, através da convergência tecnológica.

Outros dois elementos, que compõem a economia política da comunicação são apresentados por Mosco (1996) como os princípios epistemológicos e ontológicos que fundamentam a perspectiva teórica. A economia política da informação é constituída de uma epistemologia realista, inclusiva, constitutiva e crítica. Realista porque não possui enfoques idealistas e discursivos, mas "entende a realidade como a constituição mútua da observação sensorial e das práticas exploratórias” (p. 136). Inclusiva e não reducionista porque reconhece que a economia política é apenas uma das entradas para explicar as práticas sociais. Sem defender uma teoria pluralista do conhecimento, admite a validade de qualquer modelo interpretativo, "se abre a uma gama de abordagens exploratórias e rejeita a visão de que toda a realidade é redutível a uma força causal específica" (p. 137). Constitutiva porque entende a vida social como um conjunto de processos que se constituem mutuamente, interagindo uns sobre os outros. A economia política da comunicação possui, ainda, uma epistemologia crítica porque o "conhecimento é produzido através de um processo de comparação, entre formulações teóricas alternativas, entre subgrupos de uma formulação particular, e entre os dois componentes que mutuamente constituem a práxis intelectual” (p. 138). Conforme Mosco (1996), estes são o compromisso para compreender o mundo e transformá-lo.

A abordagem ontológica dá destaque, como ponto central, à mudança social, ao processo social e às relações sociais contra a tendência em pesquisa social, de con- 
centrar sua atenção em estruturas e instituições, como as empresas ou o Estado. Esta perspectiva, explica Mosco (1996), parte do princípio de que a mudança social é ubíqua, que estruturas e instituições estão sempre mudando e que, portanto, é mais útil desenvolver pontos de análise que caracterizam processos do que nomear instituições.

Três pontos são importantes na composição de uma teoria substantiva da economia política, salienta Mosco (1998), que permitem a compreensão do campo social: a mercantilização, a espacialização e a estruturação. A primeira diz respeito ao processo de transformar bens e serviços que adquirem um valor em função de seu uso, em mercadorias que ganham valor no mercado. De acordo com o autor, o processo de mercantilização é importante para os estudos da economia política por dois fatores: pelas práticas e tecnologias informacionais que contribuem para o processo de mercantilização geral em curso na sociedade e pela mercantilização como ponto chave para compreensão das práticas e instituições informacionais específicas.

Os outros dois pontos que o autor considera importantes têm uma forte relação com a mercantilização e completam a ideia de uma visão centrada na organização de negócios e nas relações de trabalho. A espacialização diz respeito ao processo de superação das limitações de espaço e tempo na sociedade. Os teóricos contemporâneos, aponta Mosco (1998), acreditam que o capitalismo transformou a noção de espaço. Hoje, pessoas, produtos e mensagens estão em algum lugar, contudo, a ideia de lugar sofreu alterações significativas. A espacialização abrange o processo de globalização, quer dizer, a reestruturação mundial das indústrias e corporações empresariais. Isso significa que os empreendimentos comerciais se utilizam das tecnologias de informação e comunicação para desenvolver a integração dos negócios.

A estruturação se concentra em descrever como as ações humanas constituem as estruturas, especialmente das organizações governamentais e de negócios, incluindo nisso as relações entre os atores envolvidos, os processos e as práticas sociais. Portanto, a análise político-econômica amplia a noção "de classe social para além de seu sentido estrutural, definido em termos de por que uns têm posses e outros não, para incorporar tanto a significação relacional quanto a constitucional do conceito" (Mosco, 1998: 109). Deste modo, para estudar a dimensão relacional das classes sociais é preciso estabelecer as conexões entre capital e trabalho e as formas como o trabalho se organiza nesta relação. A economia política da comunicação busca fazer pesquisas que registrem as injustiças nos sistemas de informação, principalmente no tocante ao acesso aos meios de informação e a reprodução destas injustiças nas instituições sociais em relação ao trabalho.

A partir daqui, torna-se necessário descrever alguns aspectos do contexto contemporâneo, na perspectiva da economia política da comunicação, para se compreender as principais mudanças macroestruturais, ocorridas nas últimas décadas, que influenciaram e continuam influenciando o funcionamento das indústrias dos meios de comunicação. 
Em primeiro lugar, o capitalismo atual vive uma reconfiguração evidente que começou há cerca de 40 anos. O quadro é composto pela transformação de pelo menos três setores. Conforme Brittos (2002), isto se deve, à globalização acelerada, que atende a um movimento de expansão do capital, seja por meio da progressiva ocupação de novos espaços para inversão, por parte das corporações transnacionais, seja através do aumento do fluxo livre dos recursos diretamente financeiros. À tecnologia, que, também, tem uma função importante, aponta o autor, principalmente os satélites e redes terrestres de transmissão de dados que auxiliam, de forma eficaz, no funcionamento sincronizado dos mercados e na transmissão ágil de informações entre diversas unidades das empresas. O outro setor que contribui para a reestruturação capitalista é a política neoliberal, através da liberalização, privatização e desregulamentação, que abre novos espaços para atuação do capital, passando a ocupar lugares até então de privilégio do Estado.

Segundo Harvey (2010), em meados dos anos 1960 já havia uma evidente incapacidade do fordismo, sistema de produção em massa caracterizado pela linha de montagem e mecanização, de lidar com as contradições que o capitalismo apresentava. Os problemas enfrentados por todos os setores econômicos podiam ser resumidos em um termo: rigidez. Diante da crise as corporações se viram obrigadas a buscar uma nova lógica para o sistema de produção.

A mudança tecnológica, a automação, a busca de novas linhas de produto e nichos de mercado, a dispersão geográfica para zonas de controle do trabalho mais fácil, as fusões e medidas para acelerar o tempo de giro do capital passaram ao primeiro plano das estratégias corporativas de sobrevivência (...) (Harvey, 2010: 137-140).

Neste sentido, as décadas de 1970 e 80 foram muito conturbadas, e estas experiências resultaram em um regime de acumulação inteiramente novo, combinado com um sistema de regulamentação política e social bem distinto, observa Harvey (2010). A este período o autor denominou de acumulação flexível para opor-se à rigidez do fordismo. "Ela se apóia na flexibilidade dos processos de trabalho, dos mercados de trabalho, dos produtos e padrões de consumo" (Harvey, 2010: 140).

Desta maneira, o que marcou o capitalismo contemporâneo, a partir da década de 1970, foram a ascensão do papel da informação no processo produtivo, a reestruturação das relações de trabalho e a aceleração da inovação tecnológica, resume Brittos (2002). No sistema capitalista de acumulação flexível, como diz Harvey (2010), a economia de escala baseada na produção em massa foi substituída pela de escopo, sistema de produção flexível que permite uma aceleração do ritmo da inovação do produto, ao lado da exploração de nichos de mercado altamente especializados e em pequenos lotes. Diante da volatilidade do mercado, do aumento da competição e do 
enfraquecimento dos sindicatos, os contratos de trabalho tornam-se mais flexíveis com perda de direitos e precarização. O autor destaca, ainda, a desregulamentação que significou o aumento do monopólio em vários setores e as maciças fusões que deram origem aos grandes conglomerados.

Bolaño (2008) esclarece que a ideologia neoliberal é baseada na política de redução dos gastos sociais e de enxugamento do Estado. Conforme o autor, a onda neoliberal resulta da condição dos Estados nacionais serem obrigados a se submeter às exigências do capital financeiro, do capital que se globaliza. A nova estruturação da produção industrial capitalista ocorrida na passagem do século XX para o século XXI transformou, significativamente, também os meios de comunicação, tanto do ponto de vista tecnológico, quanto administrativo. Essa transformação alterou igualmente a concepção de informação, um dos produtos da indústria cultural. Ganharam espaço, ainda, neste mercado global, o entretenimento e os serviços ao consumidor. Ter presente que, neste contexto, a informação é uma mercadoria se torna um fator importante quando se pretende analisar a programação radiojornalística.

\section{A indústria cultural do rádio}

Assim, é de suma importância a compreensão deste modelo produtivo de maximização do lucro, por parte dos donos, no caso desta pesquisa, de emissoras de rádio, para se adequarem e sobreviverem à atual fase de acumulação flexível. Os dirigentes de negócios de mídia, cujos produtos são bens intangíveis, de alto valor de mercado, devem saber que, para obter sucesso, na era do capitalismo globalizado são necessárias algumas medidas: considerar informação e prestação de serviço como suas mercadorias; essas têm de estar ao dispor de um receptor cada vez mais ativo; encontrar-se em todos os suportes tecnológicos possíveis; e pertencer a um grupo de comunicação, de preferência hegemônico, seja em nível nacional, regional ou local.

A perspectiva teórica da economia política da comunicação reúne elementos importantes para se estudar a programação informativa do rádio contemporâneo, principalmente, por dois aspectos. Primeiro, porque permite abordar o veículo na condição de indústria cultural, reunindo os vários fatores que exercem influência sobre ele como os grupos de mídia, a propriedade privada, a globalização, as novas tecnologias de informação e comunicação, as relações dos atores envolvidos. Segundo, porque a organização da programação de uma emissora reflete a sua estrutura, como negócio de comunicação, portanto, é necessário considerar, nessa análise, que a produção e transmissão de seu produto devem ser explicadas, também, quanto ao funcionamento gerencial e financeiro da empresa de rádio.

A economia política da comunicação francesa define o rádio e a televisão como indústrias constitutivas do sistema de cultura de onda, isso quer dizer que a área 
central do controle do processo produtivo é a programação e não a edição como no cinema, por exemplo, conforme explica Bolaño (2012: 4).

No rádio e na TV, o produto é constituído de uma grade de programação, transmitida diariamente, cuja estrutura é definida de acordo com hábitos de audiência, em função de horário e padrões de comportamento de um público que se procura fidelizar, pois o financiamento depende, não do pagamento de ingresso ou da compra de uma mercadoria individualizada, mas de um "terceiro pagante", que pode ser o Estado (rádio pública), ou os anunciantes (rádio comercial).

A denominação cultura de onda se refere ao aparato tecnológico formador das indústrias do rádio e da televisão: o sistema broadcasting. Entretanto, Bolaño (2012), salienta que a definição não é inerente ao aspecto tecnológico, mas ao aspecto histórico, ou seja, as relações entre desenvolvimento tecnológico, mudanças sociais, e forma cultural, que envolveram o surgimento do broadcasting.

Buscando refletir sobre as indústrias do rádio e da televisão a partir da perspectiva da economia política da comunicação, Bolaño (2012), explica que elas estão sujeitas a três forças sociais. Essas forças seriam, do que se depreende das considerações do autor, o Estado, o mercado e a sociedade. Cada uma dessas forças sociais cumpre uma função, respectivamente: propaganda, publicidade e programa. "A função propaganda está ligada aos interesses do Estado (...). A função publicidade é precisamente aquela vinculada ao processo de acumulação do capital monopolista" (Bolaño, 2012: 5). A função programa está relacionada à produção de bens intangíveis, mas para que aconteça, ela necessita da articulação entre as duas funções anteriores e, ainda, estar inserida no âmbito social. Segundo o autor, a função programa “(...) se refere essencialmente à exigência que se faz a qualquer indústria cultural de atender a necessidades de reprodução simbólica do mundo da vida de homens e mulheres que compõe aquele público consumidor de cultura, transformado, assim, em audiência" (Bolaño, 2012: 5).

A definição do rádio como cultura de onda torna complexa a realização de reflexões e análise sobre o meio, pois implica enxergá-lo a partir de um contexto que envolve as relações econômicas, sociais e de poder que se estabelecem ao longo do processo de funcionamento dessa indústria informacional. No entanto, busca, também, tornar essas reflexões mais profundas e abrangentes, uma vez que necessita considerar o objeto em sua totalidade, o que significa fazer cruzamentos entre os vários campos que o afetam.

A palavra que melhor explica como o meio de comunicação rádio chega à contemporaneidade é movimento. O veículo move-se em relação ao suporte de transmissão, ao de recepção, ainda mais variado, ao modo de produção, e, por tudo 
isso, ao aspecto conceitual que precisa dar conta desse novo rádio. O percurso, desde o seu surgimento, foi de grandes transformações e adaptações a cada novo contexto que se configurava. Contudo, o momento atual evidencia que mudanças cada vez mais rápidas estão em processo. A noção de movimento, portanto, marca este deslocar-se rumo a um outro, modificado, adequado, que se mostrará como, na chegada.

O surgimento da radiodifusão sonora está estreitamente vinculado à expansão das indústrias da cultura, do entretenimento e dos aparelhos elétricos nos Estados Unidos. O primeiro transmissor portátil foi patenteado em 1920, pela Westinghouse Co., obtendo grande sucesso, e a venda de receptores se tornou um bom negócio com a participação de outras quatro indústrias, relata Kischinhevsky (2007). Foi também a Westinghouse que inaugurou, tecnicamente, o rádio no Brasil, naquele 7 de setembro de 1922, através de 80 receptores importados e uma emissora de 500 watts, instalada no alto do Corcovado, no Rio de Janeiro, assinala Ortriwano (1985).

Kischinhevsky (2007: 83) chama a atenção que o rádio, como novo negócio, despertou o interesse dos proprietários de jornais americanos. "A multiplicação de emissoras foi quase instantânea: em 1922, o governo já tinha concedido 254 licenças de funcionamento". Assim como nos Estados Unidos, no Brasil a iniciativa privada exerceu o predomínio sobre o veículo que surgia de tal forma que, "nos anos 30 e 40, estabeleceria para as famílias americanas um horário nobre de consumo de bens simbólicos, assim, como ocorreria nos lares brasileiros", salienta Kischinhevsky (2007: 84). Num modelo baseado na estratégica ausência do Estado, a semelhança histórica fez da radiodifusão a indústria cultural mais promissora do país com a chegada de multinacionais e agências de publicidade americanas, no Brasil do pós-guerra, aponta o autor.

Conforme Ortriwano (1985), foi a partir de meados dos anos 1930 que o rádio causou um grande impacto político e econômico na sociedade brasileira, por um lado, ditando comportamentos e mobilizando as massas, por outro, fortalecendo o ramo das agências de publicidade e o consumo de produtos. Para a autora (1985: 19), o veículo auxiliou no desenvolvimento nacional como um todo e seu impacto "foi muito mais profundo do que aquele que a televisão viria a produzir trinta anos depois".

A autorização oficial para a veiculação de anúncios, em 1932, transformou rapidamente o rádio em empresa de comunicação. Moreira (1991) ratifica que o Brasil adotou o modelo de radiodifusão norte-americano e passou a distribuir concessões a particulares, para exploração comercial do novo meio. Segundo Moreira (1991), em toda a década de 1930 o rádio divulgou, exclusivamente, anúncios de produtos e estabelecimentos brasileiros. Foi somente a partir de 1941 que os Estados Unidos começam, efetivamente, a divulgar "o american way of life, ou seja: um estilo de vida compatível com o consumo de produtos tipicamente norte-americanos, desde Coca-Cola até as revistas do Pato Donald" (Moreira, 1991: 24). Além das empresas que lançam seus produtos no mercado nacional, chegam também às grandes agências de publicidade que têm no rádio o meio mais cobiçado, salienta a autora. 
Analisando o processo de modernização no país, Ortiz (2006) descreve que até 1935 o rádio se organiza e funciona basicamente de modo não comercial e experimental. Este quadro começa a se modificar “(...) com a introdução dos rádios de válvula na década de 30, o que vem baratear os custos de produção dos aparelhos e possibilitar sua difusão junto a um público ouvinte mais amplo" (Ortiz, 2006: 39). O autor destaca que em 1952 quando a legislação aumenta o percentual permitido de publicidade para $20 \%$ a dimensão comercial se acentua, há um crescimento significativo do número de emissoras e a implantação do sistema radiofônico brasileiro se estrutura a partir de uma estreita relação com as multinacionais. Com a vinda das grandes companhias surgem também as agências que administram as contas destas e, através de um meio como o rádio, o mercado publicitário encontra espaço para prosperar. "Nas décadas de $40 \mathrm{e}$ 50 o setor publicitário se desenvolve em estreita relação com as matrizes americanas, que trazem com elas as técnicas de vendas de produtos", aponta Ortiz (2006: 44).

A passagem dos anos de 1950 para os 1960 marcam uma etapa de transição do capitalismo brasileiro. Como explica Fonseca (2008), é a fase de transição do modelo de industrialização restringida (1933-1955), para a fase de industrialização pesada (1956-1961) ou monopólica. A autora aponta que os meios de comunicação entram na década de 1960 em completa transição: a mídia impressa passava por grandes inovações, principalmente gráficas e editoriais; o rádio, em crise, passava por uma ampla reestruturação, modificando sua programação para música gravada, esportes, notícias e prestação de serviço ao invés das radionovelas e programas de auditório e a televisão se afirmava como mídia de massa por excelência.

Kischinhevsky (2007) chama a atenção para outro aspecto, a mudança de posicionamento do governo. No período entre 1950-1960, o Estado começava a ceder espaço para o capital, através de políticas de comunicação mais flexíveis e mesmo permitindo a criação de monopólios privados. Nos anos de 1970 a televisão é a mídia que simboliza a completa consolidação das indústrias culturais no país, conforme Fonseca (2008). Contudo, na década de 1960, o rádio permaneceu consolidado, com ampla penetração popular e como meio de comunicação hegemônico, se institucionalizando como indústria cultural.

Para descrever como funciona a indústria cultural do rádio, recorreu-se a Zallo (1988). Segundo o autor, a indústria do audiovisual contínuo requer uma produção complexa e variada, com divulgação única e recepção múltipla, como é o caso do rádio e da televisão. Para Zallo (1988), os processos laborais são de produção simultâneas e emissão sequenciais, organizados por uma programação que garante a continuidade e cotidianidade das emissões e integra os trabalhos criativos e técnicos no mesmo processo. No entanto, Zallo (1988) assinala que rádio e televisão são indústrias culturais diferentes com alguns aspectos em comum.

O rádio foi o meio de comunicação, aponta Zallo (1988), que instituiu as formas de funcionamento do negócio como produção, gestão, formação de demanda e 
usos sociais; de financiamento para o estabelecimento de uma programação variada e de consumo massivo; formas de processos de organização do trabalho plenamente industrial, ou seja, a simultaneidade da atividade da empresa/indústria com os trabalhos criativos e técnicos, entre outras. Os sistemas de rádio e televisão viveram, desde que foram criados, o paradigma da "forma de aparato", conforme Zallo (1988: 129), ou seja, os aparatos de produção e distribuição do conhecimento e da cultura "estão separados tanto dos trabalhadores intelectuais e técnicos que produzem para eles, como daqueles que consomem os produtos culturais".

Outro aspecto, resultante do processo de industrialização, foi a substituição progressiva de uma política de programação como informar, educar, divertir, por uma economia de programação. Essa passagem, portanto, adéqua as emissoras ao capitalismo globalizante, uma vez que os veículos ao invés de terem uma política editorial baseada em princípios jornalísticos como interesse público e contribuírem para o esclarecimento do cidadão, conforme Fonseca (2008) passam a ter uma nova concepção de programação, baseada em informação, entretenimento e prestação de serviço como mercadoria, produtos que quanto mais alto seu valor de consumo, mais bem sucedidas serão avaliadas as rádios. "A tese de ‘o público quer' dá uma margem de manobra decisiva para enquadrar a produção utilizando a grade de programação decidida sob a pressão do mecanismo publicitário" (Zallo, 1988: 131).

Embora a obra de Zallo seja de 1988, e, as duas décadas posteriores tenham sido de profundas mudanças, principalmente do ponto de vista tecnológico, que alteraram enormemente as formas de fazer e ouvir rádio, o autor antevê algumas tendências do veículo, na atualidade, como predomínio de emissoras especializadas, desgaste de formatos tradicionais dos anos 1960 como Top-40 e o convívio de audiências e rádios bem distintas: de um lado, grandes redes, com afiliadas nos grandes centros urbanos e o domínio de grupos de comunicação e, de outro, pequenas emissoras locais em diferentes áreas geográficas.

"O rádio é a área em que mais se confundem programação e publicidade", aponta Zallo (1988: 138) acertadamente. Em relação às emissoras FM, uma parte da programação musical é, ao mesmo tempo, promoção da indústria fonográfica, e verifica-se hoje, também, a inserção de publicidade apresentada como prestação de serviço. Essa confusão se mantém no padrão AM. Segundo o autor, as emissoras comerciais se tornam grandes espetáculos sonoros devido às constantes interrupções na programação sem solução de continuidade e nos repetidos comunicados, no uso de patrocínios, nos roteiros de compra e nos diálogos com anunciantes.

A mescla desordenada entre o que é uma e outra não é mero acaso ou simples falta de clareza na roteirização da programação. É elemento estratégico de valorização da publicidade, através do uso de técnicas jornalísticas, no intuito de dar mais credibilidade e isenção aos anúncios. Os patrocinadores de um programa, por exemplo, exigem que o apresentador diga de sua própria voz a marca e o slogan dos produtos 
publicitários. Se este recurso é bom para os anunciantes, é ruim para a credibilidade e para a qualidade dos conteúdos transmitidos pelas rádios. Um dilema, portanto, que vem de tempos e deve ser resolvido pelas emissoras, é buscar maneiras de se fortalecer financeiramente, aumentar a audiência e, ao mesmo tempo, oferecer conteúdo qualificado, cumprindo sua função de bem informar.

\section{Considerações finais}

O rádio está sendo desafiado a redefinir o seu conteúdo, adverte o autor espanhol Moragas (2012), por um lado, devido ao impacto das novas tecnologias da informação no sistema de mídia, mas também, por outro, pelo esgotamento de suas próprias rotinas de produção de conteúdos e de programação. Para o autor, o que se verifica hoje, nas emissoras, em relação às informações transmitidas é mais improvisação do que análise, mais encontros de bate-papo do que programas documentados, repetição excessiva da programação em grades de diferentes emissoras e, ainda, o empobrecimento da linguagem radiofônica. Conforme Moragas (2012: 01), a dimensão profissional do veículo, responsável por dirigir a produção dos conteúdos e a organização da programação, deve ser melhorada.

Conforme Ferraretto (2010: 544), os conglomerados de comunicação, que se consolidam entre os anos de 1970 e 1980, "articulam-se no campo da propriedade cruzada dos meios, controlando, de modo simultâneo, jornais, emissoras de rádio e/ou TV". Contudo, em mercados de menor porte, algumas empresas conseguiram enfrentar a forte concorrência do capital estrangeiro, isso devido à profissionalização de empresários do setor. Ferraretto (2009) registra que as empresas radiofônicas se favoreceram com algumas consequências do regime militar, a partir do golpe de 1964, como os investimentos em infraestrutura. Por outro lado, a repressão política atrasou o desenvolvimento do radiojornalismo no país, salienta o autor. "Já segmentado, de 1980 até 2000 , o rádio registra uma queda de 8,1 para 4,9\% na sua participação no bolo publicitário", constata Ferraretto (2009: 108), e complementa que o resultado deste empobrecimento no mercado de rádio foi a formação de redes via satélite, que diminuíram os custos de produção das emissoras.

No início dos anos 1990, com a reconfiguração do capitalismo principalmente através dos avanços tecnológicos no campo midiático, "altera-se a regulamentação e novas operações radiofônicas surgem no mercado, perante iniciativas de antigos e novos players", dessa pluralidade de competidores e de opções emerge uma forte concorrência entre os agentes para conquistar o consumidor final e o anunciante, aponta Brittos (2002: 40). Em 1995 são estabelecidas as condições para a definição de um novo período do rádio brasileiro que Brittos (2002) denomina de fase da multiplicidade da oferta. Segundo o autor, verifica-se uma maior variedade de produtos disponíveis e uma mudança quantitativa e qualitativa dos processos midiáticos. Esta 
fase se caracteriza pelo redimensionamento dos mercados que agora é global e pelo maior número de meios concorrendo entre si.

Nos últimos 20 anos, porém, com a proliferação cada vez mais intensa e acelerada das novas tecnologias de informação e comunicação, as múltiplas formas de convergência transformaram "a estrutura das empresas de radiodifusão sonora, eliminando funções, alterando hierarquias e modificando padrões de trabalho", assinala Ferraretto (2009: 109). Estas mudanças significam a adaptação do veículo ao capitalismo global. Desse modo, a fórmula mais comum, encontrada pelos grupos de comunicação de grande e médio porte foi "a criação de portais de conteúdo na internet, englobando conteúdos gerados - ou retrabalhados a partir destes - por seus veículos tradicionais de imprensa, rádio e/ou televisão", aponta Ferraretto (2010: 545), desenvolvendo-se, exatamente, essa fase da multiplicidade de oferta, com o aumento da quantidade de agentes produtores e também de produtos disponíveis. $\mathrm{Na}$ contemporaneidade se vive a fase da convergência midiática com a maximização da estrutura produtiva e de mão de obra e o rádio está se adaptando a este período.

A partir da conceituação de convergência jornalística de Salaverría, Garcia Avilés e Masip (2008), Ferraretto e Kischinhevsky (2010: 174), apontam para a importância de compreender as "novas lógicas de produção, comercialização, distribuição e consumo de conteúdos radiofônicos", a partir dos quatro âmbitos de convergência: tecnológica, empresarial, profissional e de conteúdo. Os autores descrevem os âmbitos da convergência jornalística adaptados para o rádio.

a) Tecnológico - Engloba a infraestrutura de produção, distribuição e recepção de conteúdos em suportes digitais, tais como computadores, gravadores, softwares de edição e gestão de conteúdos, bases de dados, redes de fibra óptica etc.

b) Empresarial - Compreende a origem e a composição dos capitais que controlam os grupos de comunicação, suas alianças, fusões e aquisições, participações societárias cruzadas etc.

c) Profissional - A integração de estruturas para produção de conteúdos a serem distribuídos em múltiplos suportes, as mudanças nas rotinas e nas relações de trabalho e as questões relacionadas à formação e à qualificação de mão-de-obra em ambiente multimídia.

d) Dos conteúdos - A produção de conteúdos, com a exploração de novas linguagens e formatos possibilitados pela hibridização de formas simbólicas desenvolvidas para difusão em multiplataforma (Ferraretto e Kischinhevsky, 2010: 176).

A partir da análise dos quatro âmbitos de convergência jornalística, adaptados ao rádio, Ferraretto e Kischinhevsky (2010), concluem que se verificam mais continuidades do que rupturas no desenvolvimento do veículo nos últimos 30 anos. De 
forma geral, a linguagem radiofônica permanece a mesma; na grade de programação das emissoras, mantêm-se os tipos de programas já testados e aprovados ao longo do tempo; e nem mesmo a participação efetiva dos ouvintes aumentou, apesar das inúmeras formas tecnológicas criadas para isso.

A convergência jornalística, nos seus quatro âmbitos, alterou os processos produtivos e gerenciais do rádio. Estas transformações ocorreram de forma mais intensa em alguns campos do que em outros e, ainda, acarretaram vários prejuízos como no âmbito profissional, concretamente, e muitas melhorias como no tecnológico, visivelmente. No âmbito dos conteúdos, a melhoria na qualidade do radiojornalismo, por exemplo, é muito mais uma possibilidade do que, de fato, a utilização, em larga escala, pelas emissoras, dos recursos multiplataforma para o surgimento de novas linguagens e formatos. No empresarial, observa-se, muito mais, uma continuidade do modelo de oligopólios, concentrado nas mãos dos grandes grupos de mídia, do que inovações nos formatos de negócio. As grandes mudanças e adaptações vivenciadas pelo rádio, no transcurso de sua história, servem para mostrar a capacidade que este meio tem de se moldar às inovações, mesmo que lentamente, em alguns períodos.

Veridiana Pivetta de Mello

Professora da Universidade de Santa Cruz do Sul - RS verimello@hotmail.com

Recebido em dezembro de 2014.

Aceito em março de 2015.

\section{Referências}

BRITTOS, Valério Cruz. O rádio brasileiro na fase da multiplicidade da oferta. Verso $\mathcal{E}$ Reverso, São Leopoldo: Editora da Unisinos, ano 16, n. 35, jul.-dez. 2002.

BOLAÑO, César. Desafios da economia política da informação, da comunicação e da cultura frente às inovações tecnológicas e à mudança social: a atual batalha epistemológica do pensamento crítico latino-americano. In: BRITTOS, Valério Cruz (Org.). Economia política da comunicação. São Leopoldo: Editora Unisinos, 2008.

. Considerações sobre a economia política do rádio no Brasil. Revista de Economía Politica de las Tecnologias de la Información y Comunicación. Revista Eptic On Line, v. XIV, n. 2 May - Ago, 2012. Disponível em:

http://www.seer.ufs.br/index.php/eptic/article/viewFile/417/331. Acesso em: 29 set. 2012. FERRARETTO, Luiz Artur. O novo rádio pós-fordista. In: LEVACOV, Marília et al. Tendências na comunicaşão. Porto Alegre: L\&PM. 1998.

. Rádio e capitalismo no Brasil: uma abordagem histórica. In: HAUSSEN, Doris Fagundes e BRITTOS, Valério Cruz (Orgs.). Economia política, comunicaşão e cultura. Porto Alegre: EDIPUCRS, 2009. 
Alterações no modelo comunicacional radiofônico: perspectivas de conteúdo em um cenário de convergência tecnológica e multiplicidade da oferta. In: FERRARETTO, Luiz Artur e KLÖCKNER, Luciano (Orgs.). E o rádio?: novos horizontes midiáticos. Dados eletrônicos. Porto Alegre: Edipucrs, 2010.

e KISCHINHEVSKY, Marcelo. Rádio e convergência: uma abordagem pela economia política da comunicação. Revista Famecos, Porto Alegre, v. 17, n. 3, setembro/dezembro 2010. Disponível em:

http://revistaseletronicas.pucrs.br/ojs/index.php/revistafamecos/article/viewFile/8185/5873. Acesso em: 22 out. 2011.

FONSECA, Virginia. Indústria de notícias: capitalismo e novas tecnologias no jornalismo contemporâneo. Porto Alegre: Editora da UFRGS, 2008.

GARCÍA AVILÉS, Jose A.; SALAVERRÍA, Ramón e MASIP, Pere. Convergencia periodística en los medios de comunicación. Propuesta de definición conceptual y operativa. In: I Congreso de la Asociación Española de Investigadores en Comunicación, Santiago de Compostela, 30 enero a 1 febrero de 2008. Anais ... Disponível em http://www.ae-ic.org/ santiago2008/contents/pdf/comunicaciones/134.pdf. Acesso em: 22 out. 2012.

HARVEY, David. Condição pós-moderna. 19a ed. São Paulo: Loyola, 2010.

KISCHINHEVSKY, Marcelo. O rádio sem ondas: convergência digital e novos desafios na radiofusão. Rio de Janeiro: E-papers, 2007.

MORAGAS, Miguel de. Interpretar la comunicación: estúdios sobre medios em América y Europa. Barcelona: Gedisa, 2011.

. La radio y el Día Mundial de la Radio de 2012. Dossiers. Portal de La Comunicación InCom. Disponível em:

http://www.portalcomunicacion.com/monograficos_txt.asp?id=195\&txt=165.

MOREIRA, Sonia Virgínia. O rádio no Brasil. Rio de Janeiro: Rio Fundo, 1991.

MOSCO, Vincent. The political economy of communication. London: Sage, 1996.

. Repensando e renovando a economia política da informação. Perspectiva em

ciência da informação. Belo Horizonte, v. 3, n.2, jul./dez. 1998. Disponível em http://www. eci.ufmg.br/pcionline/index.php/pci/article/viewFile/599/368. Acesso em: 02 de jun. 2009. ORTIZ, Renato. A moderna tradição brasileira: cultura brasileira e indústria cultural. $5^{\text {a }}$ ed. São Paulo: Brasiliense, 2006.

ORTRIWANO, Gisela Swetlana. A informação no rádio: os grupos de poder e a determinação dos conteúdos. $2^{\mathrm{a}}$ ed. São Paulo: Summus, 1985.

ZALLO, Ramón. Economía de la comunicación y la cultura. Madrid: Akal, 1988. 


\section{Resumo}

Para compreender a programação informativa no contexto do capitalismo global e o rádio como indústria cultural, tem-se como objetivo desse artigo descrever os pressupostos da economia política da comunicação, bem como a indústria cultural do rádio. A pesquisa visa mapear a formação do rádio até os dias mais atuais e mostrar os caminhos evolutivos do veículo na conjuntura do capitalismo globalizante e como ele se refletiu neste contexto de novas tecnologias.

\section{Palavras-chave}

Rádio. Economia política da comunicação. Indústria cultural.

\section{Abstract}

To understand the informative programming in the context of global capitalism and the radio as a cultural industry, we have the objective of this article is to describe the assumptions of the political economy of communication and cultural radio industry. The research aims to map the formation of even the most radio today and show the evolutionary paths of the vehicle in the globalizing capitalism situation and how it was reflected in this context of new technologies.

\section{Keywords}

Radio. Political economy of communication. Cultural industry. 